\title{
MODELING TEMPERATURE AND SALT CONCENTRATION DISTRIBUTIONS IN DIRECT CONTACT MEMBRANE DISTILLATION
}

\author{
Ali K. Abdel-Rahman \\ Associate Professor, Department of Mechanical Engineering \\ Faculty of Engineering, Assiut University, Assiut 71516, EGYPT \\ E-mail: nada_ali54@yahoo.com
}

(Received June 21, 2008 Accepted August 14, 2008)

Modern desalination technologies, applied to seawater and brackish water, offer effective alternatives in a variety of circumstances. Because of its low energy consumption, accessible running conditions and simple maintenance, membrane distillation (MD) has become one of the cheapest technologies for seawater desalination. The membrane distillation driving force is the transmembrane vapor pressure difference that may be maintained with an aqueous solution colder than the feed solution in direct contact with the permeate side of the membrane giving rise to the configuration known as direct contact membrane distillation (DCMD).

The main objective of the present study is to provide a detailed numerical analysis of the heat and mass transfer in DCMD and to offer useful basic detailed information about the nature of the process that is needed for process improvement and optimization. Moreover, the present study is carried out to investigate the effect of parameters such as the inlet temperatures of the hot and cold solutions, the concentration of the feed (hot) solution, the inlet velocity of the hot and cold solutions on the process characteristics of DCMD desalination evaluated in terms of the permeate flux and the process thermal efficiency.

The direct contact membrane distillation process has been modeled as a two-dimensional coupled problem in which a simultaneous numerical solution of the momentum, energy and diffusion equations of the feed and cold solutions have been carried out with permeation taken into account. Velocity and temperature distributions inside the membrane feed and cold solution channels are obtained. Some of the principal conclusions drawn from the present study are: (1) increasing the inlet temperature of the hot solution has a major effect on the permeate flux, (2) increasing the feed water salt concentration decreases the permeate flux, (3) the inlet velocities of the hot and cold solutions have a relatively strong effect on the permeate flux.

KEYWORDS: Distillation; Direct contact membrane distillation; Modeling; Temperature polarization; Concentration polarization. 


\section{NOMENCLATURE}

$\begin{array}{ll}\text { Alphabetic Symbols } \\ c & \text { concentration }(\mathrm{kg} / \mathrm{kg}, \%) \\ c_{p} & \text { specific heat capacity }(\mathrm{kJ} / \mathrm{kg} \mathrm{K}) \\ D_{s} & \text { solute diffusion coefficient }\left(\mathrm{m}^{2} / \mathrm{s}\right) \\ H & \text { channel height }(\mathrm{m}) \\ J_{v} & \text { mass flux }\left(\mathrm{kg} / \mathrm{m}^{2} . \mathrm{s}\right) \\ k_{s} & \text { solute thermal conductivity }(\mathrm{W} / \mathrm{m} \mathrm{K}) \\ L & \text { channel length }(\mathrm{m}) \\ p & \text { pressure }(\mathrm{Pa}) \\ S_{\Phi} & \text { source term of the variable } \phi \\ S_{p} & \text { coefficient in the discretized source } \\ & \text { term } \\ S_{u} & \text { coefficient in the discretized source } \\ & \text { term } \\ T & \text { temperature }\left({ }^{\circ} \mathrm{C}\right) \\ u & \text { streamwise velocity }(\mathrm{m} / \mathrm{s}) \\ v & \text { velocity in } y \text { direction }(\mathrm{m} / \mathrm{s}) \\ x & \text { Cartesian coordinate in the } \\ & \text { streamwise direction }\end{array}$

y Cartesian coordinate normal to the membrane

\section{Greek Symbols}

$\delta \quad$ membrane thickness (m)

$\varepsilon \quad$ membrane porosity (\%)

$\phi \quad$ any of variables to be solved

$\Gamma_{\Phi}$ diffusion coefficient of variable $\phi$

$\mu \quad$ dynamic viscosity (Pa.$s)$

$v \quad$ kinematics viscosity $=\mu / \rho\left(\mathrm{m}^{2} / \mathrm{s}\right)$

$\rho$ density $\left(\mathrm{kg} / \mathrm{m}^{3}\right)$

$\tau$ membrane tortuosity

\section{Subscripts}

$\begin{array}{ll}b & \text { bulk } \\ h & \text { hot stream } \\ i & \text { inlet } \\ c & \text { cold stream } \\ m & \text { membrane } \\ s & \text { solute, or solid }\end{array}$

\section{INTRODUCTION}

Recently, scarcity of potable water has become a major concern in many countries and therefore new techniques have been adapted in those countries to produce fresh water. Because of its low energy consumption, accessible running conditions and simple maintenance, membrane distillation (MD) has become one of the cheapest technologies for seawater desalination. Membrane distillation is an emerging technology for separations that are traditionally accomplished by conventional separation processes such as distillation or reverse osmosis. Since its appearance, MD claims to be a cost effective separation process that can utilize low-grade waste and/or alternative energy sources such as solar and geothermal energies. The potential advantages of MD process in comparison to the conventional separation processes rely on the lower operating temperature and hydrostatic pressure. Feed solutions having temperatures much lower than its boiling point under pressures near atmosphere can be used.

Membrane distillation is a thermally driven process, in which only vapor molecules are transported through porous hydrophobic membranes. The liquid feed to be treated by MD must be in direct contact with one side of the membrane and does not penetrate inside the dry pores of the membranes. The hydrophobic nature of the membrane prevents liquid solutions from entering its pores due to the surface tension forces. As a result, liquid/vapor interfaces are formed at the entrances of the membrane pores. The MD driving force is the transmembrane vapor pressure difference that can be maintained with an aqueous solution colder than the feed solution in direct contact with the permeate side of the membrane giving rise to the configuration known as direct contact membrane distillation (DCMD) [1]. The transmembrane temperature 
difference induces a vapor pressure difference. Consequently, volatile molecules evaporate at the hot liquid/vapor interface, cross the membrane in vapor phase and condense in the cold liquid/vapor interface inside the membrane module.

In membrane distillation the desired product can be either the permeate or the concentrate solution. Applications have been reported in the literature for (1) production of pure water from brackish water or seawater [2,3] and (2) concentration of fruit juices $[4,5]$. As an attractive separation process, MD has been the subject of worldwide academic studies by many experimentalist and theoreticians [6-10]. Martinez-Diez et al. [6] experimentally studied the effects of temperature, feed concentration and flow rate on permeate flux and heat lost by conduction through the membrane in a direct contact-type module. They found that for the feed studied, both high temperature and flow rate promote flux and decrease relative heat loss. Termpiyakul et al. [7] carried out an experimental study using a flat-sheet membrane to investigate the heat and mass transfer of the DCMD process. They found that the permeation fluxes increased with feed temperature and velocity, but decreased with feed concentration. The effects of temperature and concentration polarization on the reduction of vapor pressure differences across the membrane with regard to the vapor pressure differences corresponding to the bulk phases which are separated by the membrane have been studied by Martinez-Diez and Vazquez-Gonzalez [8]. They found that only the temperature polarization becomes important while concentration polarization has an insignificant influence.

Hsu et al. [2] have carried out experimental study using both the $\mathrm{NaCl}$ solution and real seawater as the feed of MD processes to investigate the differences in permeate flux, product water quality and membrane fouling. They found that the accumulation rate of membrane scale can be depressed by reducing the degree of polarization if $\mathrm{NaCl}$ solution is used as the feeding fluid; however, this kind of depression effect is not so obvious when real seawater is used as the feeding fluid.

Peng et al. [9] investigated the effects of brine temperature, salt concentration, running time and the addition of ethanol on the flux of composite membranes. Their results showed that the flux of the composite membrane did not deteriorate by adopting an additional hydrophilic membrane although durability was obviously improved.

Rodriguez-Maroto and Martinez [10] have studied the development of a transport model for a direct contact membrane distillation process in laminar flow that allows knowing the velocity and temperature profiles within the flow channels as a function of externally measured temperatures just at the entrances and exits of the flow channels in the membrane module. They applied this model to a conventional membrane module, and so calculated the difference between the bulk temperatures and the externally measured ones. Moderately important differences between both temperatures were obtained when working at low flow rates and high temperatures in their study. None of the previous studies has realized the sensitivity of the feed solution properties to the changes in both temperature and concentration. In the present work, MD is used for desalination and seawater is the hot feed solution.

Computational fluid dynamics (CFD), together with mass transfer modeling, have proved to be a powerful tool to be used in simulating the processes through DCMD of membrane modules and enable precise predictions of velocities, pressure and solute concentration which are the main variables that are crucial for the management of the DCMD process. 
The present study pertains to modeling numerically of a seawater desalination system using DCMD. The study is directed towards establishing a numerical method capable of predicting the flow and concentration characteristics of the DCMD taking into account the variable properties of the hot and cold streams. For this purpose, a finite volume discrete scheme using the SIMPLE (Semi-Implicit Method for Pressure Linked Equations) pressure-correction scheme combined with QUICK (Quadratic Upwind Interpolation Convective Kinematics) scheme in the frame of staggered grid is used.

The main objective of the present study is to provide a detailed numerical analysis of the heat and mass transfer in DCMD and to offer useful basic detailed information about the nature of the process that is needed for process improvement and optimization. Moreover, the present study is carried out to study the effect of parameters such as the inlet temperatures of the hot and cold solutions, the concentration of the feed (hot) solution, the inlet velocity of the hot and cold solutions on the desalination process characteristics of DCMD desalination evaluated in terms of the permeate flux and the process thermal efficiency.

\section{MODEL DEVELOPMENT}

The system to be studied consists of a porous hydrophobic membrane, which is held between two symmetric channels shown in Fig. 1. Hot saline solution is circulated through one of the channels and cold water through the other one. The hot and cold fluids counter-flow tangentially to the membrane surface in a flat membrane module. The temperature difference through the membrane gives rise to a water vapor pressure difference and, consequently to a water flux, $J_{v}$, through the membrane. The process is modeled by solving the 2-dimentional momentum, energy and species equations in the hot and cold solutions regions.

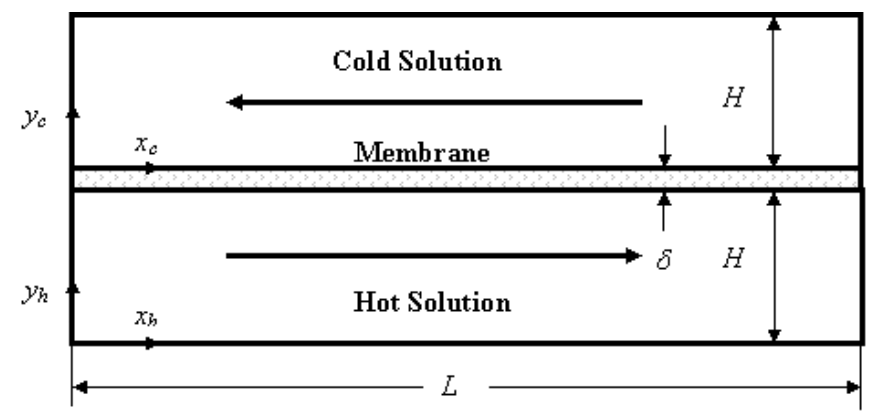

Fig. 1 Membrane module including the membrane and the hot and cold solutions channels

\subsection{The Hot Solution Region}

The hot solution flows between two parallel walls, the upper wall is hydrophobic microporous membrane and the lower one is impermeable wall. The steady state two dimensional transports of the momentum, energy, and species of the hot solution are described by the continuity, momentum, energy and species conservation equations [11]; 
$\frac{\partial u_{h}}{\partial x_{h}}+\frac{\partial v_{h}}{\partial y_{h}}=0$

$\frac{\partial\left(\rho_{s} u_{h} u_{h}\right)}{\partial x_{h}}+\frac{\partial\left(\rho_{s} v_{h} u_{h}\right)}{\partial y_{h}}-\frac{\partial}{\partial x_{h}}\left[\mu_{s}\left(\frac{\partial u_{h}}{\partial x_{h}}\right)\right]-\frac{\partial}{\partial y_{h}}\left[\mu_{s}\left(\frac{\partial u_{h}}{\partial y_{h}}\right)\right]+\frac{\partial P_{h}}{\partial x_{h}}=0$

$\frac{\partial\left(\rho_{s} u_{h} v_{h}\right)}{\partial x_{h}}+\frac{\partial\left(\rho_{s} v_{h} v_{h}\right)}{\partial y_{h}}-\frac{\partial}{\partial x_{h}}\left[\mu_{s}\left(\frac{\partial v_{h}}{\partial x_{h}}\right)\right]-\frac{\partial}{\partial y_{h}}\left[\mu_{s}\left(\frac{\partial v_{h}}{\partial y_{h}}\right)\right]+\frac{\partial P_{h}}{\partial y_{h}}=0$

Where, $u_{h}$ and $v_{h}$ are the streamwise and transverse velocity components, respectively, $P$ is the pressure, $\rho$ is the density and $\mu$ is the dynamic viscosity of the solution.

Mass transfer occurring within domains with porous walls can be mathematically expressed by the two dimensional convective and diffusion equation as follows [12];

$$
\frac{\partial\left(\rho_{s} u_{h} c_{s}\right)}{\partial x_{h}}+\frac{\partial\left(\rho_{s} v_{h} c_{s}\right)}{\partial y_{h}}-\frac{\partial}{\partial x_{h}}\left[D_{s}\left(\frac{\partial c_{s}}{\partial x_{h}}\right)\right]-\frac{\partial}{\partial y_{h}}\left[D_{s}\left(\frac{\partial c_{s}}{\partial y_{h}}\right)\right]=0
$$

Where $D_{s}$ is the solute diffusion coefficient and $c_{s}$ is the solute concentration.

Most of the previous models solve equations (1)-(4) using constant or concentration-dependent only thermophysical and flow properties. In the present study, the energy equation has to be solved to account for the temperature dependence of the above mentioned properties. For two dimensional, incompressible, steady laminar channel flows; the energy equation is given as [12]

$$
\frac{\partial\left(\rho_{s} u_{h} T_{h}\right)}{\partial x_{h}}+\frac{\partial\left(\rho_{s} v_{h} T_{h}\right)}{\partial y_{h}}-\frac{\partial}{\partial x_{h}}\left[\frac{k_{s}}{c_{p s}}\left(\frac{\partial T_{h}}{\partial x_{h}}\right)\right]-\frac{\partial}{\partial y_{h}}\left[\frac{k_{s}}{c_{p s}}\left(\frac{\partial T_{h}}{\partial y_{h}}\right)\right]=0
$$

where $k_{s}$ and $c_{p s}$ are the solution thermal conductivity and specific heat at constant pressure, respectively.

\subsection{The Membrane Domain}

In DCMD the pressure difference across the two sides of the membrane will be zero when both the feed and permeate flows are under atmospheric pressure. In this case the contribution of Poiseuille flow to mass transfer can be neglected. At a typical membrane temperature of $60^{\circ} \mathrm{C}$, and for a mean pore diameter of membranes between 0.1 and $0.5 \mu \mathrm{m}$, the mean free path of water vapor is $0.11 \mu \mathrm{m}$. Therefore, in the system where water (component $\mathrm{A}$ ) is used as volatile component Knudsen number $(K n)$ may vary from 0.2 to 1.0. As air (component B) is trapped in the pores, the permeation of water vapor through the membrane is regulated by the Knudsen-molecule diffusion transition mechanism.

For mass transfer through the membrane in DCMD, on the ground of Knudsen-molecule diffusion transition model, the following equation can be used to calculate trans-membrane mass flux, $J_{v}[13]$ : 
$J_{v}(x)=\frac{\varepsilon M_{A}}{\tau \delta} \frac{p D_{A B}}{R T_{m}} \ln \frac{\left(p-p_{p m}\right) / p D_{A B}+(3 / 4 d) \sqrt{2 \pi M_{A} / R T_{m}}}{\left(p-p_{f m}\right) / p D_{A B}+(3 / 4 d) \sqrt{2 \pi M_{A} / R T_{m}}}$

where $\varepsilon$ (porosity), $\delta$ (thickness), $d$ (pore diameter) and $\tau$ (tortuosity), which are the membrane geometrical parameters, $T_{m}$ is the hot and cold streams average temperature $(\mathrm{K}), R$ is the universal gas constant, $M_{A}$ is the water vapor molecular weight, $p_{p m}$ and $p_{f m}$ are the vapor partial pressures $(\mathrm{Pa})$ at the membrane-permeate and feed interfaces respectively calculated by using [3]:

$p^{v}=\exp \left(23.328-\frac{3841}{T-45}\right)$

$p$ is the total (air + vapor) pressure, and $D_{\mathrm{AB}}$ is the diffusion coefficient of the vapor through the air $\left(\mathrm{m}^{2} / \mathrm{s}\right)$ at a temperature ranges between 273 and $373 \mathrm{~K}$ which is estimated from the following empirical equation [3]:

$p D_{A B}=1.895 \times 10^{-5} \mathrm{~T}^{2.072}$

where the unit of $p D_{A B}$ is $\mathrm{Pa}-\mathrm{m}^{2} / \mathrm{s}$.

On the other hand, the resistances in the heat transfer process of DCMD consist of three parts: the resistance of boundary layer at the feed side, of the membrane and of the boundary layer at the permeate side. The total heat flux is transferred from the hot surface of the membrane to the cold surface of the membrane by two different parallel routes. One is by heat conduction across the membrane material $\left(Q_{\mathrm{C}}\right)$ while the other is by the mass transfer of the vapor $\left(Q_{L}\right)$

$Q_{T}=Q_{L}+Q_{C}=J_{v} \Delta H_{v}+\left(k_{m} / \delta\right)\left(T_{f m}-T_{p m}\right)$

where $\Delta H_{v}$ is the latent heat of vaporization. In Eq. (9) $k_{m}$ is the thermal conductivity of the porous membrane that can be calculated as

$k_{m}=\varepsilon k_{g}+(1-\varepsilon) k_{s}$

with $k_{g}$ and $k_{s}$ being the thermal conductivities of the gas trapped in the membrane pores and the membrane solid material, respectively [14].

\subsection{The Cold Solution Region}

The cold solution flows between two parallel walls, the lower wall is hydrophobic microporous membrane and the upper one is impermeable wall. The transport of the momentum and energy of the cold solution are described by the continuity, momentum, and energy conservation equations [11];

$$
\begin{aligned}
& \frac{\partial u_{c}}{\partial x_{c}}+\frac{\partial v_{c}}{\partial y_{c}}=0 \\
& \frac{\partial\left(\rho_{w} u_{c} u_{c}\right)}{\partial x_{c}}+\frac{\partial\left(\rho_{w} v_{c} u_{c}\right)}{\partial y_{c}}-\frac{\partial}{\partial x_{c}}\left[\mu_{w}\left(\frac{\partial u_{c}}{\partial x_{c}}\right)\right]-\frac{\partial}{\partial y_{c}}\left[\mu_{w}\left(\frac{\partial u_{c}}{\partial y_{c}}\right)\right]+\frac{\partial P_{c}}{\partial x_{c}}=0
\end{aligned}
$$




$$
\frac{\partial\left(\rho_{w} u_{c} v_{c}\right)}{\partial x_{c}}+\frac{\partial\left(\rho_{w} v_{c} v_{c}\right)}{\partial y_{c}}-\frac{\partial}{\partial x_{c}}\left[\mu_{w}\left(\frac{\partial v_{c}}{\partial x_{c}}\right)\right]-\frac{\partial}{\partial y_{c}}\left[\mu_{w}\left(\frac{\partial v_{c}}{\partial y_{c}}\right)\right]+\frac{\partial P_{c}}{\partial y_{c}}=0
$$

Where, $u_{c}$ and $v_{c}$ are the streamwise and transverse velocity components of cold stream, respectively, $P_{c}$ is the pressure, $\rho_{w}$ is the density and $\mu_{w}$ is the dynamic viscosity of water liquid.

In the present study, the energy equation has to be solved to account for the temperature dependence of the cold stream properties. For two dimensional, incompressible, steady laminar channel flows, the energy equation is given as [12]

$$
\frac{\partial\left(\rho_{w} u_{c} T_{c}\right)}{\partial x_{c}}+\frac{\partial\left(\rho_{w} v_{c} T_{c}\right)}{\partial y_{c}}-\frac{\partial}{\partial x_{c}}\left[\frac{k_{w}}{c_{p w}}\left(\frac{\partial T_{c}}{\partial x_{c}}\right)\right]-\frac{\partial}{\partial y_{c}}\left[\frac{k_{w}}{c_{p w}}\left(\frac{\partial T_{c}}{\partial y_{c}}\right)\right]=0
$$

where $k_{w}$ and $c_{p w}$ are the cold solution thermal conductivity and specific heat at constant pressure, respectively.

\subsection{Boundary Conditions}

The boundary conditions of the problem are specified as follows:

1- At the inlet of both channels, the flow is assumed to be fully developed thus a parabolic flow is specified. A uniform inflow concentration of $c_{h i}$ is specified at the inlet of the hot solution channel. A constant inlet temperature of $T_{h i}$ and $T_{c i}$ are specified at the inlet of the hot and cold channels, respectively.

2- At the lower wall of the hot channel, the tangential velocity $u$ and the transverse velocity $v$ are set to zero; the normal gradients of the concentration and temperature are set to zero.

3- At the upper wall of the cold channel, the tangential velocity $u$ and the transverse velocity $v$ are set to zero; the normal gradient of the temperature is set to zero.

4- At the membrane walls, the conditions are more complex, as flow permeates through the wall. The tangential velocity $u$ is set to zero i.e. no slip at membrane walls. Variation in permeation is modeled using the following expression;

$$
v_{m h}(x)=J_{v}(x) / \rho_{s},
$$

The boundary condition of the concentration at the membrane lower wall results from a balance of the convective and diffusive fluxes. The concentration boundary condition is given by;

$$
\left.D_{s} \frac{\partial c_{s}(x)}{\partial y}\right|_{y=H}=J_{v}(x) / \rho_{s}
$$

The boundary condition of the temperature at the membrane walls results from a balance of the convective and conductive heat fluxes. The temperature boundary condition is given by; 


$$
-\left.k_{s} \frac{\partial T(x)}{\partial y}\right|_{y=0 \text { or } H}=Q_{C}(x)+J_{v}(x) \Delta H_{v}
$$

5- At the exit, both the flow, temperature and concentration fields are assumed to obey the boundary layer approximation. It is important to mention that this treatment of the down stream end boundary condition has proved to be robust and effective in shortening the computational domain leading to a reduction of the number of grid nodes [15].

\subsection{Discretization}

The steady-state form of the conservation equations of continuity, momentum, concentration and energy can be written in a general form as [16];

$$
\frac{\partial(\rho u \phi)}{\partial x}+\frac{\partial(\rho v \phi)}{\partial y}-\frac{\partial}{\partial x}\left[\Gamma_{\phi}\left(\frac{\partial \phi}{\partial x}\right)\right]-\frac{\partial}{\partial y}\left[\Gamma_{\phi}\left(\frac{\partial \phi}{\partial y}\right)\right]-S_{\phi}=0
$$

where $\phi$ stands for any of the variables to be solved, $\Gamma_{\Phi}$ is the diffusion coefficient, and $S_{\Phi}$ is the source term of the variable $\phi$. For $\phi=u$ or $v$ and $\Gamma_{\Phi}=\mu$ and $S_{\Phi}=$ pressure gradient in the direction of flow one gets the momentum equations, while for $\phi=1$ and $\Gamma_{\Phi}=0$ one obtains the continuity equation [17]. If $\phi=T, \Gamma_{\Phi}=k / c_{p}$ and $\mathrm{S}_{\Phi}=0$ one gets the energy equation. When $\phi=c, \Gamma_{\Phi}=D$, and $S_{\Phi}=0$ the general equation stands for the mass transfer equation [18].

All the governing equations are discretized by first integrating them over a control volume (CV) and then approximating the fluxes of variable crossing the faces of each cell in terms of the values at the neighboring grid points. In the present work, a QUICK scheme, which can handle uniform and non-uniform grid systems, is used to finite differencing the convective terms and to secure second order accuracy in central differencing the diffusive fluxes. The resulting finite-difference equations for a point $P$ in relation with the neighboring points ( $E$ : East, $W$ : West, $N$ : North, $S$ : South, $E E$ : East of East, etc.) are described in the form of [19],

$$
\begin{array}{ll}
a_{p} \phi_{p}=\sum_{i} a_{i} \phi_{i}+S_{u} \Delta V, & i=E, W, N, S, E E, W W, N N, S S, \\
a_{p}=\sum_{i} a_{i}-S_{p} \Delta V, & i=E, W, N, S, E E, W W, N N, S S,
\end{array}
$$

where $\Delta V$ is the cell volume and $S_{p}$ and $S_{u}$ are the coefficients appearing in the following linearized source term;

$$
S_{\phi}=S_{u}+S_{p} \phi
$$

The finite difference coefficients $a_{i}$ are the coefficients describing the magnitudes of the sum of the convective and diffusive fluxes and contain the geometric properties of the control volume [15]. 


\subsection{Numerical procedure}

The present study utilizes a modified version of the SIMPLE procedures developed by Partakar and Spalding [19]. The main steps of the SIMPLE algorithm are;

1- A pressure field is assumed in the hot channel,

2- It is used to obtain approximate velocity field in the hot channel,

3- The velocity and pressure fields (in the hot channel) are corrected if the former does not satisfy the continuity equation,

4- Solve the discretization equations for the other $\phi$ 's such as temperature and concentration (in the hot channel) provided their influence on the flow field.

5- Do step 1-4 in the cold channel. Calculate the membrane permeation and heat transfer through the membrane.

6- Return to step 2 with the corrected velocity field and the new values of all other $\phi$ 's and then the steps 2-5 are repeated until a converged solution is obtained.

In the present work, the cross-stream distribution of $u$-velocity component is adjusted to satisfy the overall continuity (conservation of the mass flow are integrated over a cross-stream line) whereas the pressure field is adjusted to satisfy the overall momentum balance. This procedure is important especially for the present problem in which the flow is changed as the flow moves downstream due to the permeation through the membrane surface $[15,17]$. Moreover, the cross-stream distribution of the concentration (in the hot channel) is adjusted to satisfy the overall mass concentration of the permeated species.

An alternating direction implicit (ADI) procedure has been combined with the iterative solution procedure of equations (15) to enhance isotropic propagation of a change of variables occurring at one point to the surrounding [17]. This procedure makes use of the line-by-line Tri-Diagonal Matrix Algorithm (TDMA) solver. In the ADI procedure, sweep of line-by-line integration was carried out along both northsouth grid lines and along east-west grid lines alternatively. The same procedure was applied twice for the pressure correction [15].

\subsection{Physical Properties}

The membrane solute rejection leads to the development of a solute concentration profile in the hot fluid phase adjacent to the membrane. The hot stream is seawater. Expressions for the variation of physical properties with temperature and concentration for seawater were taken from El-Dessouky and Elttouney [20]. The cold stream was liquid water subjected to temperature variations. Therefore, the transport and physical properties of the solutions, in the transport equations (1)-(13), should include the variation with the solute concentration (in the hot stream) and the solution temperature in both cold and hot streams. The correlations relative to the variation with the temperature of the physical and transport properties of the liquid water were collected from different sources [e.g. 20]. 


\section{PROCESS PARAMETERS}

The parameters to be evaluated in this work include the averaged permeate flux, the conductive and convective heat transfer, the total heat transfer, the process thermal efficiency, and the temperature and pressure polarization coefficients.

The averaged permeate flux is obtained by integrating Eq. (6) over the length of the membrane and dividing by the membrane length $(L)$

$$
J=\frac{1}{L} \int_{0}^{L} J_{v}(x) d x
$$

by integrating the second term of Eq. (9), the $x$-averaged conduction heat flux is

$$
Q_{C}=\frac{1}{L} \int_{0}^{L} Q_{C}(x) d x
$$

by integrating the first term of Eq. (9), the $x$-averaged latent heat flux is

$$
Q_{L}=\frac{1}{L} \int_{0}^{L} Q_{L}(x) d x
$$

and by integrating Eq. (9), the total heat transfer is

$$
Q_{T}=\frac{1}{L} \int_{0}^{L} Q_{T}(x) d x
$$

The process thermal efficiency can be defined as

$$
\eta_{t h}=\frac{Q_{L}}{Q_{T}}
$$

where the numerator is the heat used for the production of the distillate.

Polarization phenomena can be described using a temperature polarization coefficient (TPC) and a concentration polarization coefficient (CPC), defined as [1]:

$$
\begin{aligned}
& T P C=\frac{1}{L} \int_{0}^{L} \frac{T_{m h}(x)-T_{m c}(x)}{T_{b h}(x)-T_{b c}(x)}, \\
& C P C=\frac{1}{L} \int_{0}^{L} \frac{c_{m h}(x)-c_{m c}(x)}{c_{b h}(x)-c_{b c}(x)}=\frac{1}{L} \int_{0}^{L} \frac{c_{m h}(x)}{c_{b h}(x)}
\end{aligned}
$$

where ' $\mathrm{m}$ ' and ' $\mathrm{b}$ ' indicate the values of temperature and concentration on the membrane surface and in the bulk condition, respectively.

\section{RESULTS AND DISCUSSION}

\subsection{Model Validation}

The computations are carried out in the rectangular domain shown in Fig. 1. The main results were obtained for a computational domain of $H=0.45 \times 10^{-3} \mathrm{~m}, L=0.1 \mathrm{~m}$. The membrane employed in this study has the characteristics of 0.8 porosity $(\varepsilon)$, a nominal pore size $\left(d_{p}\right)$ of $0.2 \mu \mathrm{m}$, thermal conductivity $\left(k_{m}\right)$ of $0.055 \mathrm{~W} / \mathrm{m} \mathrm{K}$, and thickness $\left(\delta_{\mathrm{m}}\right)$ 
of $0.6 \times 10^{-4} \mathrm{~m}$. A grid-dependence analysis of the method of solution was performed. The number of elements is chosen to be $16,000(400 \times 40)$ because further refinement of the mesh to 24,000 elements produced just a $0.06 \%$ difference in $J$.

Moreover, to ensure that the numerical solution is not affected adversely by the specification of the inlet conditions to the hot and cold liquid flow channels, the sensitivity of the solution to the location where the inlet boundary conditions were specified was investigated. Comparing the velocity distributions for specifying the inlet at a distance of $x / H=100$ upstream of the channels' inlets (Fig. 1), and for specifying them at the inlet itself $(x / H=0)$, has shown no discernible differences.

On the light of the objective of the present work, the validity of the present numerical simulation has been verified by comparing results obtained from its application with the corresponding experimental results of Martinez-Diez and Vazquez-Gonzalez [8] at similar conditions. Figure 2 shows the average permeate fluxes predicted by the present model along with the experimental data of MartinezDiez and Vazquez-Gonzalez [8]. In Fig. 2 the distillate fluxes for the three recirculation rates studied (feed and permeate average velocities of 25,39 , and 53 $\mathrm{cm} / \mathrm{s}$ ) are displayed as a function of the feed temperatures when distilled water is used as feed. Results shown in Fig. 2 are obtained for both the present study and the experiment at bulk temperature difference $\left(\Delta T_{b}\right)$ of $10^{\circ} \mathrm{C}\left(\Delta T_{b}=T_{b h}-T_{b c}\right)$. A non-linear increase in the flux, as shown in Fig. 2, with increasing temperature reflects the exponential increase in the vapor pressure which provides the driving force. Figure 2 also shows that the permeate flux increases when the recirculation rate is increased. The effect of a higher recirculation rate is to increase the heat transfer coefficient and thus reduce the effect of temperature polarization. This means that the temperatures at the membrane surface more closely approximate that of the bulk streams, and thus the transmembrane temperature difference is greater. This produces a greater driving force and consequently enhances the flux. The figure shows that the present model is capable of predicting permeate fluxes with a reasonable accuracy compared with the experimental results of [8].

The phenomenon of the temperature polarization causes the temperatures at the membrane surfaces to differ from the bulk temperatures of the feed and the distillate. This phenomenon causes an important loss in the driving force for transport with regard to the imposed force even when the feed is water. The corresponding temperature polarization coefficients (TPC) were calculated using the present numerical model (Eq. 21) and compared with the results obtained by Martinez-Diez and Vazquez-Gonzalez [8]. These results are shown in Fig. 3 which indicates that the present model is capable of predicting TPC with a reasonable accuracy. The results shown in Fig. 3 suggest that the TPC is an important factor affecting the mass flux as $T P C$ values range between 0.4 and 0.6 . Moreover, in the temperature interval studied $\left(T_{h b}\right.$ varied from $20^{\circ} \mathrm{C}$ to $50^{\circ} \mathrm{C}$ ), TPC varied significantly, it decreases as the temperature increases. This is due to the exponential rise of the vapor pressure which makes the permeate flux increase substantially as the temperature rises. These larger mass fluxes involve higher heat fluxes through the liquid phases, which in turn increase the temperature gradient in the liquid boundary layers and so the temperature polarization. For this reason $J$ does not increase with the temperature as fast as the vapor pressure does. 


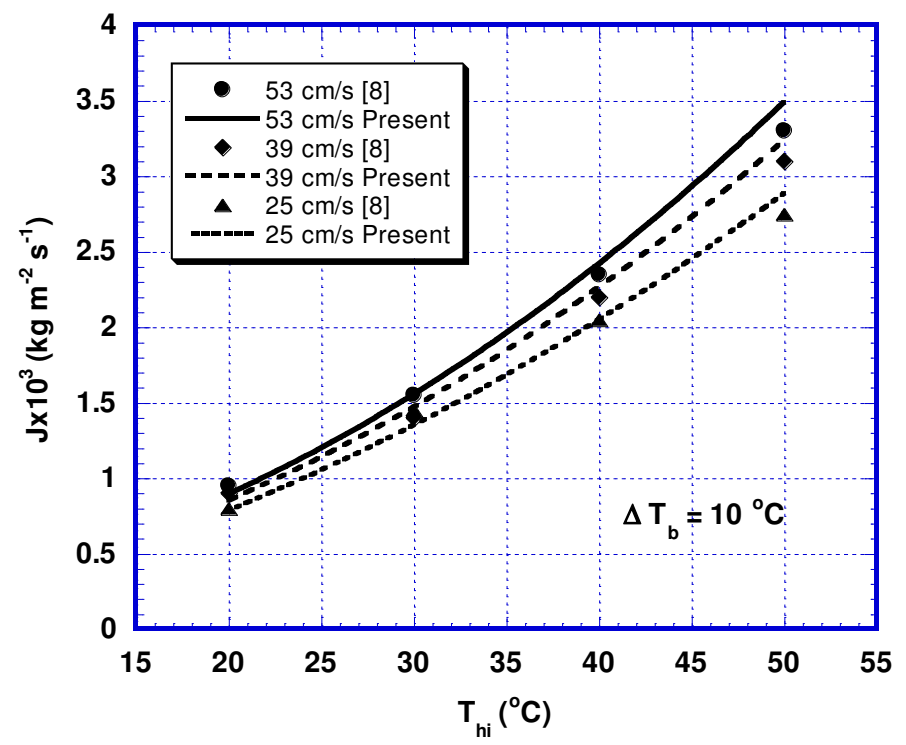

Fig. 2 Water flux vs. feed temperature for feed/permeate inlet velocity of 25, 39 and 53 $\mathrm{cm} / \mathrm{s}$.

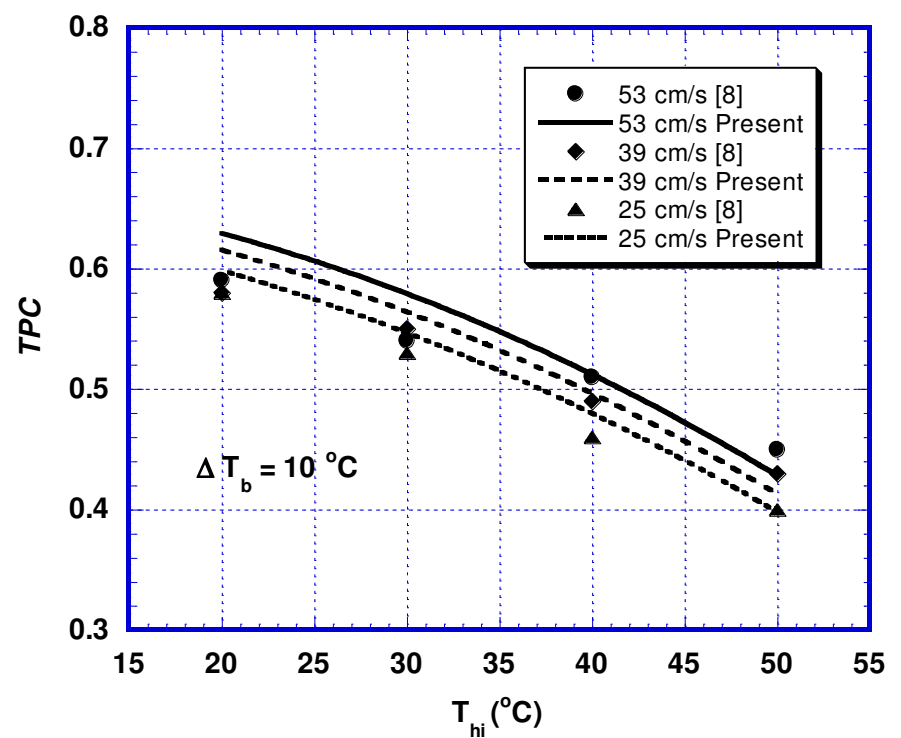

Fig. 3 TPC vs. feed temperature for feed/permeate inlet velocity of 25,39 and $53 \mathrm{~cm} / \mathrm{s}$.

\subsection{Model Predictions}

In the present study, series of simulations were carried out to examine the predictability power of the present model for the DCMD desalination processes. Numerical simulations are performed to study the effects of varying the controlling parameters such as the feed (seawater) temperature, velocity and concentration on the performance of the DCMD desalination processes. The analysis is made for the inlet temperature of the feed solution $\left(T_{\mathrm{hi}}\right)$ in the range of $40-75^{\circ} \mathrm{C}$ at $5^{\circ} \mathrm{C}$ increments, feed solution inlet 
concentrations in the range of $0-25 \mathrm{wt} \%$ (from brackish water to saturation) at $5 \mathrm{wt} \%$ increments, feed and cold solution velocities $\left(u_{\mathrm{hi}}, u_{\mathrm{ci}}\right)$ in the range of $0.06-0.14 \mathrm{~m} / \mathrm{s}$ at $0.04 \mathrm{~m} / \mathrm{s}$ increments. The cold solution inlet temperature $\left(T_{\mathrm{ci}}\right)$ of $25^{\circ} \mathrm{C}$ is kept constant throughout this study. The membrane employed in the present study is the same as the one used in the validation step.

\subsubsection{Velocity, temperature and concentration profiles}

In order to demonstrate that the developed model is capable of predicting physically realistic distributions of the quantities of interest, the streamwise velocity, temperature, and concentration profiles results were obtained for feed concentration of $3.5 \mathrm{wt} \%$, and feed and cold streams inlet velocities of $0.14 \mathrm{~m} / \mathrm{s}$. Examples of the computed results for the above mentioned quantities are shown in Figs. 4-8.

For the case under study, streamwise velocity profiles in the hot and cold channels at the downstream locations of $x / L$ of 0.9 (hot channel) and 0.1 (cold channel) at different feed temperatures of $45,55,65$, and $75^{\circ} \mathrm{C}$ are shown in Figs. 4 and 5, respectively. Figure 4 shows that the velocity is decelerated near the membrane wall (upper side) with the deceleration increases as the feed temperature is increased. This velocity deceleration could be attributed to the mass permeation (withdrawal) from the hot channel to the cold channel through the membrane wall which is increased as the temperature difference is increased. This effect is similar to that occurs in a channel flow with fluid suction from the wall [10].

On the other hand, Fig. 5 shows that the velocity is accelerated near the membrane wall (lower side) with the acceleration increases as the feed temperature is increased. Again it is worth mentioning that this velocity distribution characteristic is similar to that of a channel flow with fluid injection from the wall [15]. This velocity acceleration could be attributed to the mass permeation (addition) from the hot channel to the cold channel through the membrane which is increased as the temperature difference is increased.

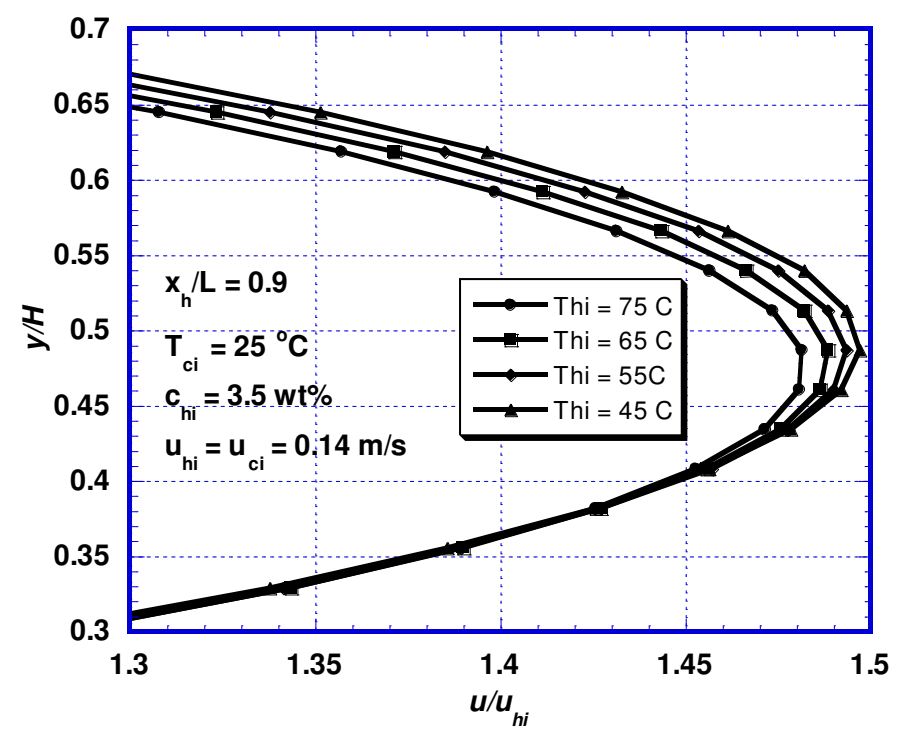

Fig. 4 Velocity profiles at different feed temperature in the hot channel. 


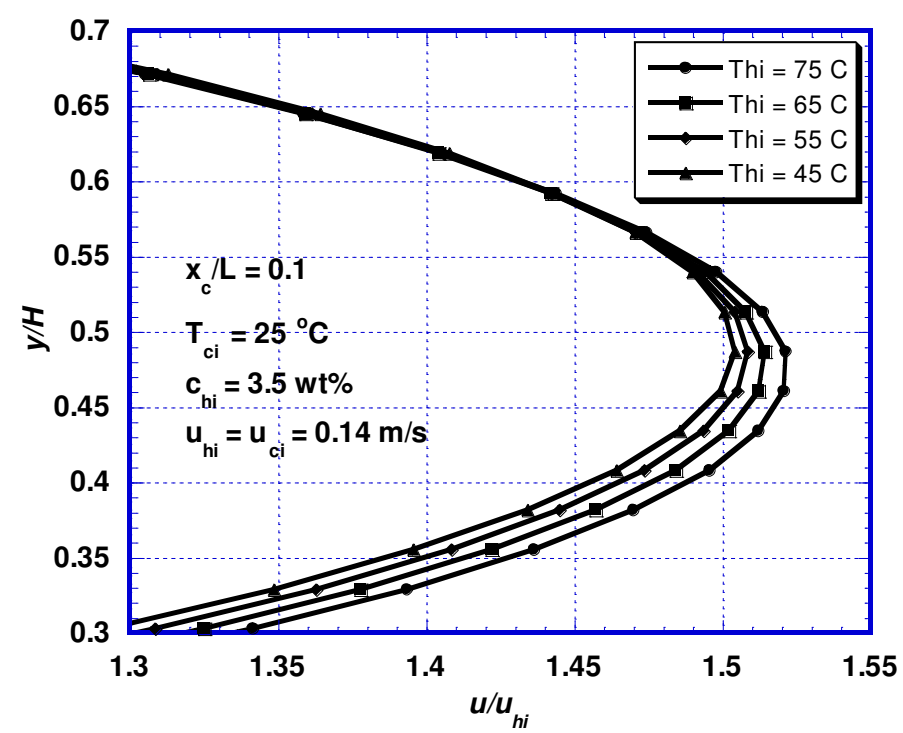

Fig. 5 Velocity profiles at different feed temperature in cold channel.

Similarly, the local temperature profiles $T(x / L=$ constant, $y)$ along the $y$ coordinate will vary remarkably with the hot solution inlet temperatures as shown in Figs. 6 and 7. Figure 6 shows an example of the temperature profiles obtained numerically in the present study in the cold channel at $x / L=0.1$ (downstream of the cold channel) when the cold solution inlet temperature was $25^{\circ} \mathrm{C}$. It is found that the temperature profiles in the hot channel are very similar to these in the cold channel as shown in Fig. 7. The plotted values are referred to the corresponding local temperature on the membrane cold/hot surfaces $\left(T_{m c}, T_{m h}\right)$. It can be seen from these figures that considerable temperature drops occurred in the thermal boundary layers. The temperature drop $\left(T-T_{m c}\right)$ is negative in the cold channel as the membrane wall temperature is greater than the bulk temperature due to the hot vapor permeation from the hot channel to the cold channel. It is to be taken into account that the whole bulk temperature drop through the hot channel (not shown here), was in the range of $5-15^{\circ} \mathrm{C}$ (as $T_{h i}$ changed from $45-75^{\circ} \mathrm{C}$ ). Temperature drop in the thermal boundary layers ranged from about $18^{\circ} \mathrm{C}$ (corresponding to the hot stream inlet temperature of $75^{\circ} \mathrm{C}$ ) to about $5.5^{\circ} \mathrm{C}$ (for the hot stream inlet temperature of $45^{\circ} \mathrm{C}$ ). The latter is indicative of important temperature polarization phenomena occurred in the system studied. The results shown in the figures for each $T_{h i}$ reflect the characteristic temperature distribution of a countercurrent flow heat exchanger.

Figure 8 shows an example of the concentration distribution obtained numerically in the present study at different feed temperatures in the hot channel (at $x / L=0.9$ ). The case considered here is for feed concentration of $3.5 \mathrm{wt} \%$ (seawater), cold stream temperature of $25^{\circ} \mathrm{C}$ and hot/cold stream velocities of $0.14 \mathrm{~m} / \mathrm{s}$. It is obvious from the figure that the hot solution concentration at the membrane wall is increased as the feed temperature is increased due to the enhancement of the pure water permeation through the membrane as a result of the feed temperature increase (as will be seen later) and also by referring to Figs. 4 and 5. The concentration in the vicinity of 
the membrane wall increases compared with the bulk value suggesting that the species convection towards the wall is much larger than the species diffusion away from the wall. This concentration build up near the membrane wall adversely affects the driving force of membrane distillation as will be seen later.

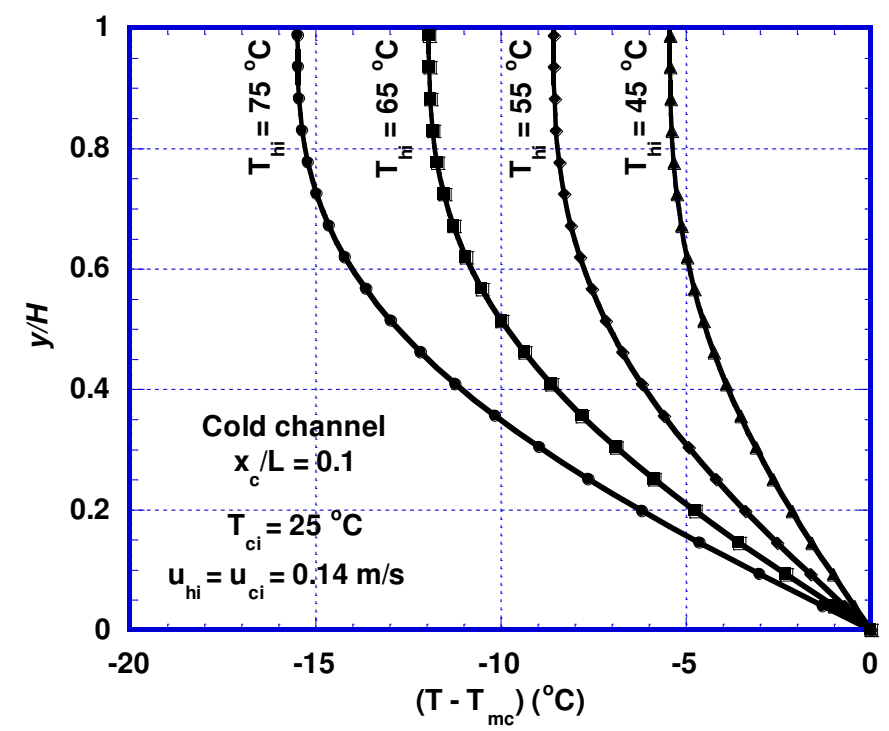

Fig. 6 Temperature profiles at different feed temperatures in the cold channel

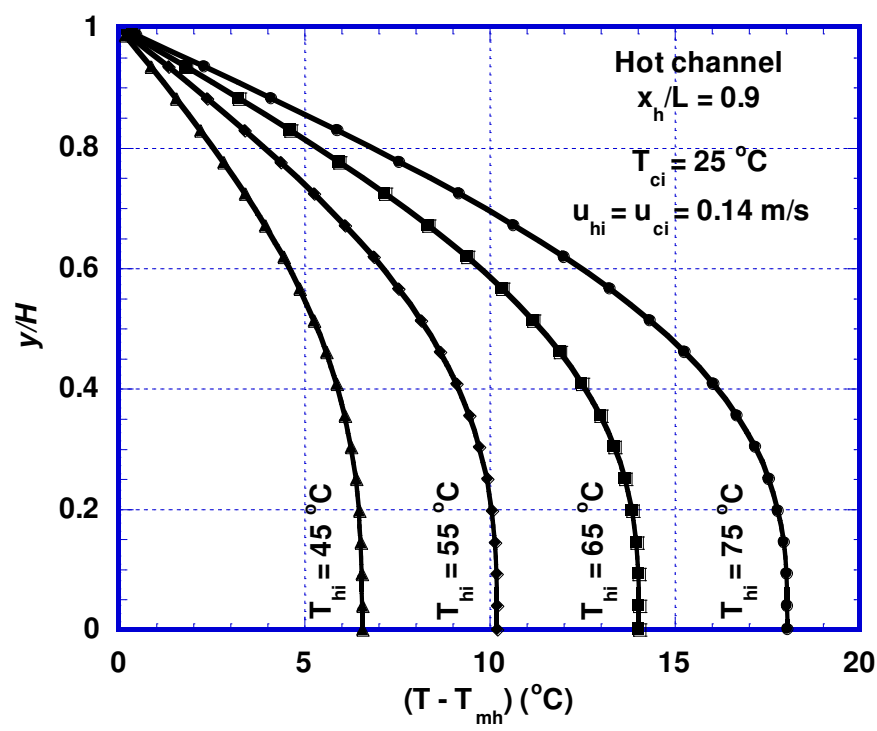

Fig. 7 Temperature profiles at different feed temperatures in the hot channel

\subsubsection{Effect of feed temperature and concentration on the DCMD}

The operating parameters that affect DCMD desalination performance are the feed and permeate temperatures, feed concentration and flow rate (which affect the heat transfer coefficients). For example, performance (evaluated in terms of the flux) improves 
monotonically as the feed temperature is increased from its lower limit of $0^{\circ} \mathrm{C}$ to its upper limit of $100^{\circ} \mathrm{C}$ (limits for MD of dilute aqueous solutions) [21]. It is worth mentioning that the feed and permeate flow rates exhibit similar influence as explained in [21].

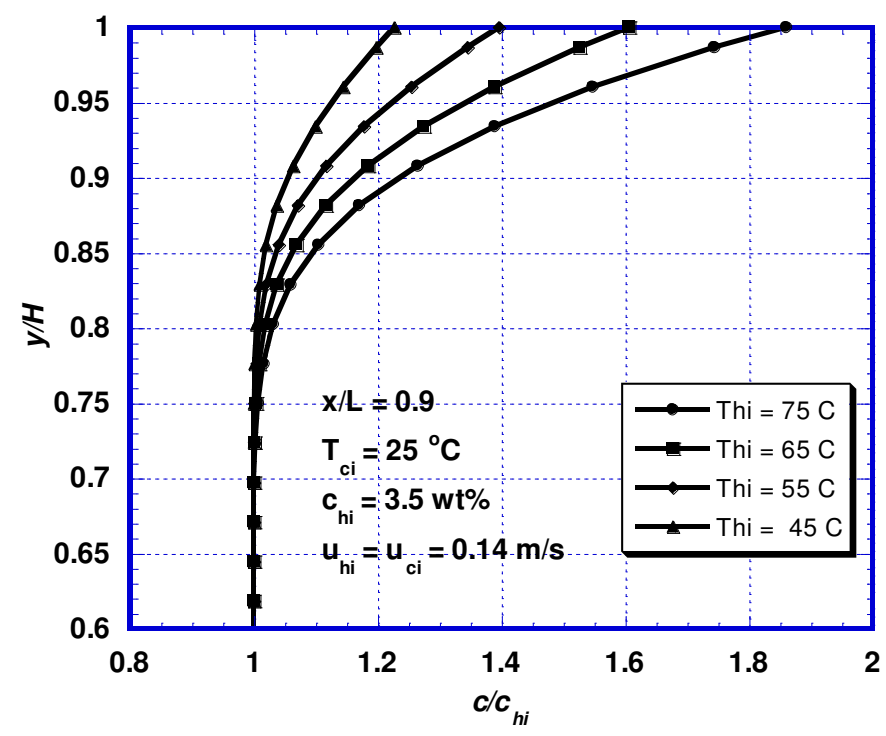

Fig. 8 Concentration profiles at different feed temperatures in hot channel

Computer simulations used to investigate the influence of the feed concentration at different feed temperatures for a specific case of DCMD desalination performance are reported here. Figure 9 shows the results obtained in the present study for the distillate fluxes as a function of the feed concentration when different feed temperatures are considered. Figure 9 shows that the permeation flux at different values of feed temperature at constant distillate temperature of $25^{\circ} \mathrm{C}$ is increased as the feed temperature is increased for the feed concentration range considered. A non-linear increase in the flux with increasing temperature reflects the exponential increase in the vapor pressure which provides the driving force. Figure 9 also shows that the flux decreases in an approximately linear way with the feed concentration in the studied range (particularly at low feed temperature). This can be attributed to the fact that the permeation driving force (vapor pressure) is increased as the feed temperature is increased and decreased as the feed concentration is increased. These results agree very well with the experimental results of Qtaishat et al. [3] and Yun et al. [22].

\subsubsection{Effect of feed temperature and flow rate on the DCMD}

The variation of permeate flux with the feed temperature for different values of feed velocities, $u_{h i}$, is shown in Fig. 10. Figure 10 shows that the permeate flux increase substantially with the increase in the feed temperature, which can be attributed to the exponential increase in the permeation driving force (vapor pressure) with temperature. It can be also noted that as the feed velocity (flow rate) increases, the permeate flux increases. The permeate flux increases as the recirculation rate is to increase the heat 
transfer coefficient and thus reduce the effect of temperature polarization (TPC is increased with $u_{h i}$ as shown in Fig. 11). This means that the temperatures at the membrane surface more closely approximate that of the bulk streams, and thus the trans-membrane temperature difference is greater. This produces a greater driving force and consequently enhances the flux. The figure also shows that the effect of increasing the feed velocity becomes more significant as the feed temperature is increased. Again as shown in Fig. 10, a non-linear increase in the flux with increasing temperature reflects the exponential increase in the vapor pressure which provides the driving force.

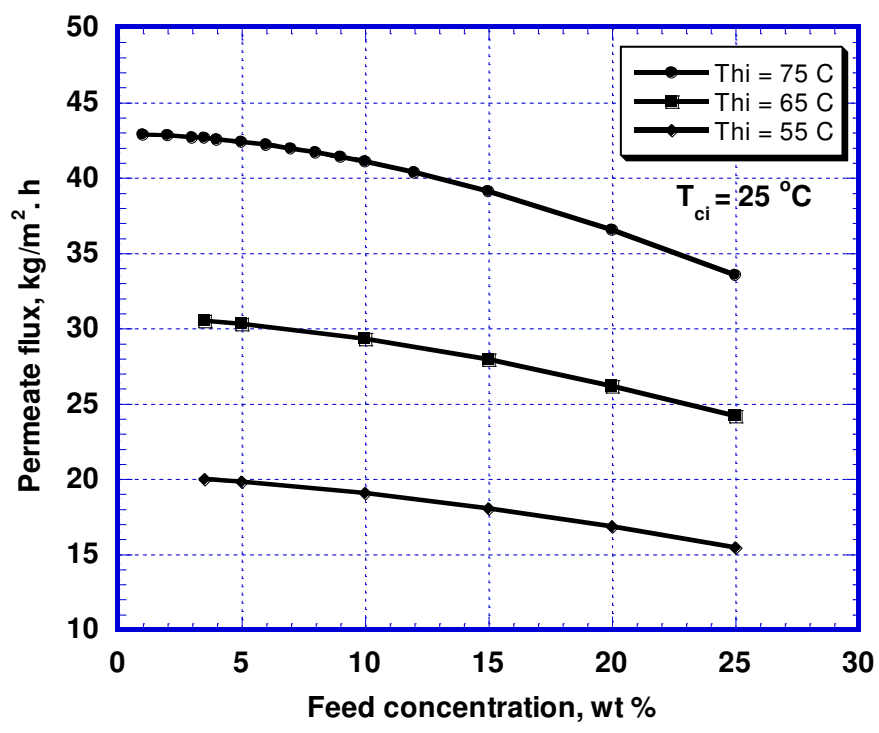

Fig. 9 Effect of feed concentration on the permeate flux

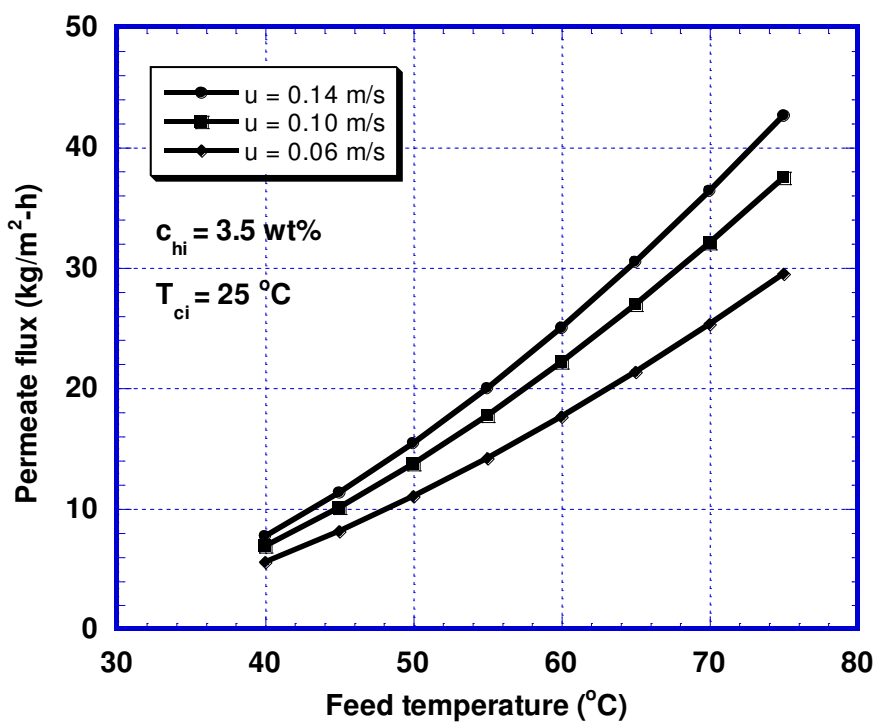

Fig. 10 Effect of feed temperature on permeate flux for different flow rates. 


\subsubsection{Temperature and concentration polarization coefficient}

A commonly used measure of the magnitudes of the boundary layer heat transfer resistances relative to the total heat transfer resistance of the system is given by the temperature polarization coefficient (TPC), Eq. (21). The phenomenon of the temperature polarization causes the temperature at the membrane surfaces to differ from the bulk temperature in the feed and in the distillate. This phenomenon is present even when the feed is water and causes an important loss in the driving force for transport with regard to the imposed force. The value of $T P C$ approaches unity for well designed systems, and it approaches zero for systems that are hampered by large boundary layer resistances (high degrees of temperature and concentration polarization) [8]. The highest values of TPC reported in the literature for a pure water DCMD fall within a range of 0.4 (high fluxes) to 0.7 (low fluxes) [8]. Figure 11 shows the calculated values of TPC for the case of DCMD desalination results described above (feed concentration of $3.5 \mathrm{wt} \%$ (seawater), cold stream temperature of $25^{\circ} \mathrm{C}$ ). As shown in the figure, at very low $T_{h i}$ (low flux), TPC ranges from 0.4515 for the feed velocity of $0.06 \mathrm{~m} / \mathrm{s}$ to 0.4614 for the feed velocity of $0.14 \mathrm{~m} / \mathrm{s}$. At higher $T_{h i}$ (high flux), the value of $T P C$ is always above the 0.32 value.

As indicated previously, after evaluating $T P C$, the concentration polarization coefficient $(C P C)$ was evaluated from Eq. (22). The membrane wall concentration was as much as $20-80 \%$ higher than the bulk concentration $\left(c_{m h} / c_{b h}=1.2-1.8\right)$ as shown in Fig. 8. In the present study, this concentration increase means a decrease of the vapor pressure by about $3-12 \%$. As a consequence the increase of the concentration polarization leads to a small reduction in the permeate flux in the studied cases. This is an important result as concentration polarization is a major cause of flux reduction in other membrane processes such as ultrafiltration and reverse osmosis. Figure 12 shows the calculated values of $C P C$ for the case of DCMD desalination results described above. In the present study, $C P C$ is increased linearly with feed temperatures as shown in Fig. 12. The effect of feed flow rates on $C P C$ is relatively small at lower values of the feed temperature and it becomes more pronounced at higher values.

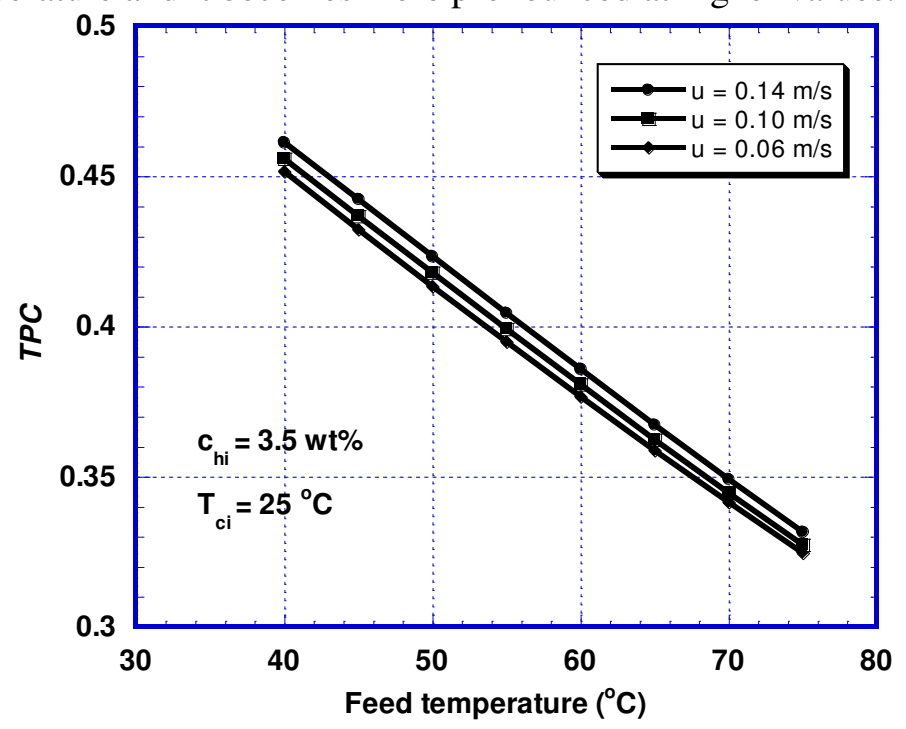

Fig. $11 T P C$ vs feed temperature for different flow rates. 


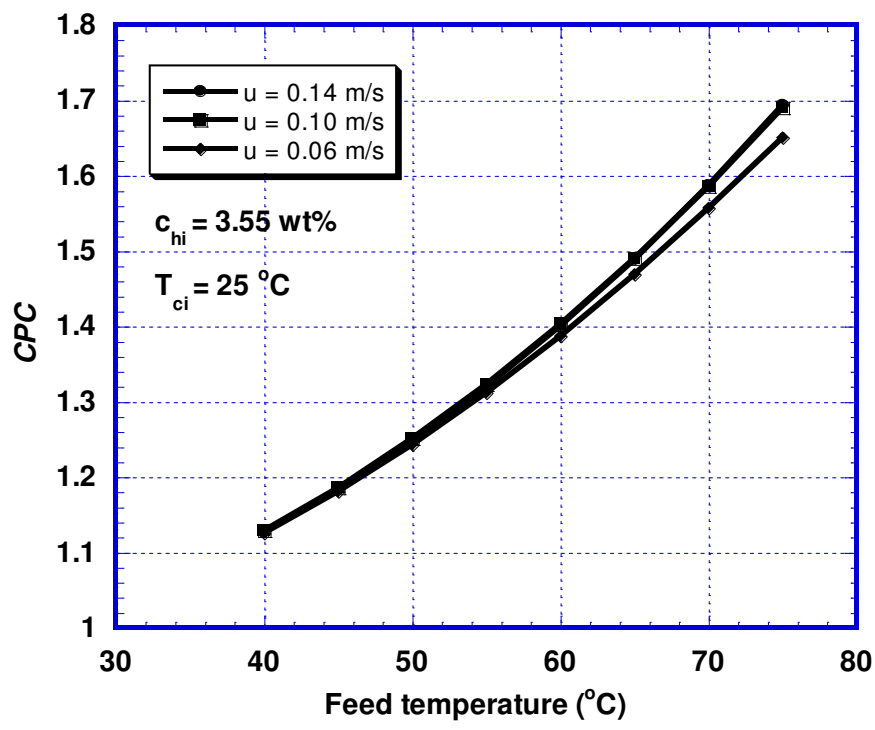

Fig. $12 C P C$ vs feed temperature for different flow rates.

\subsubsection{Thermal efficiency}

One of the primary concerns in DCMD desalination, with regard to effective energy consumption, is limiting the amount of heat lost in the process. The amount of heat that is lost by conduction through the membrane and the membrane module is a function of the module design and the thermal conductivities of the module and membrane materials.

In order to estimate the heat lost, calculations were performed in the following way. The latent heat of evaporation is the heat used effectively and is obtained from the permeate flux. The increase in heat of the cooling water is a sum of the latent heat of evaporation and the conduction heat lost through the membrane from the feed to cooling water. Figure 13 shows that the effect of the feed temperatures is to increase the thermal efficiency for different flow rates. Increasing the feed temperature of the hot solution thus does not only increase the permeate flux but also improves the thermal efficiency as the figure indicates.

\section{CONCLUSIONS}

In this study, numerical analysis of DCMD performance for sea and brackish water desalination has been made. The obtained results in the present study indicate that the DCMD performance is superior to that of reverse osmosis in terms of both flux and salt rejection (100\% rejection can be theoretically achieved in MD). The proposed method succeeds in predicting the effects of the controlling parameters on the DCMD performance. The following points can be drawn from the results of the present numerical simulation:

(1) A salt concentration (up to $25 \mathrm{wt} \%$ ) has shown to have an almost negligible effect on the performance of DCMD desalination. 
(2) Feed temperature is an important factor for the capacity of DCMD process. The distillate flux increases with increasing the feed temperature,

(3) The distillate flux decreases as the feed concentration increases,

(4) The distillate flux increases with the flow rate through the feed channel,

(5) The process thermal efficiency is enhanced as the feed temperature is increased.

(6) The influence of temperature polarization on the effectiveness of DCMD desalination has been found to be important. satisfactory.

The results were compared with the available data and the agreement is

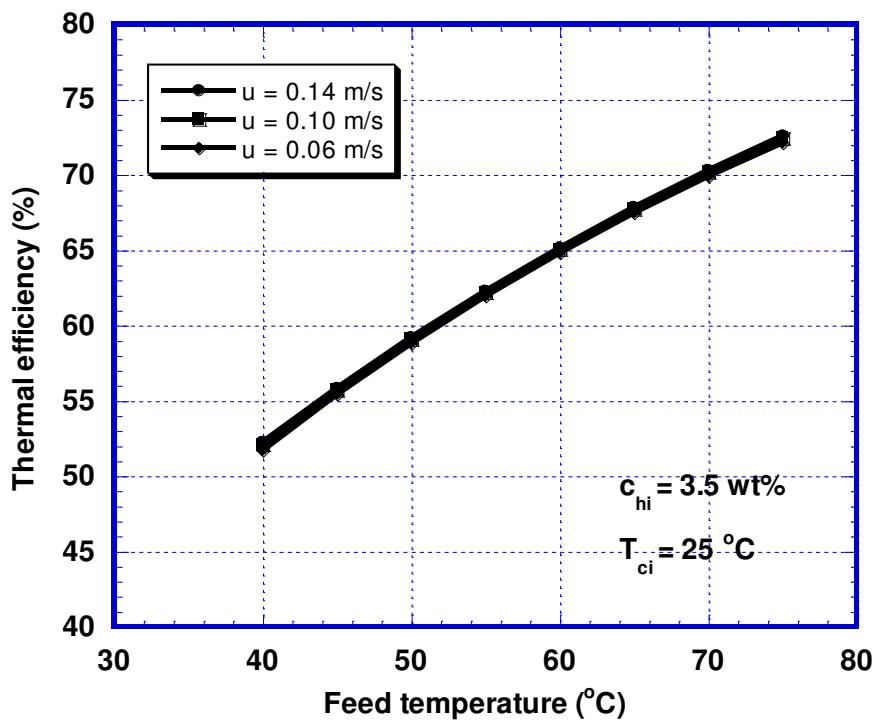

Fig. 13 Thermal efficiency vs feed temperature for different flow rates.

\section{REFERENCES}

[1] Fortunato Laganà, Giuseppe Barbieri, and Enrico Drioli: Direct contact membrane distillation: modeling and concentration experiments, J. of Membr. Sci. 166 (2000) 1-11.

[2] Hsu S.T., Cheng K.T., and Chiou J.S: Seawater desalination by direct contact membrane distillation, Desalination 143 (2002) 279-287.

[3] Qtaishat M., Matsuura T., Kruczek B., and Khayet M.: Heat and mass transfer analysis in direct contact membrane distillation, Desalination 219 (2008) 272292.

[4] Sergey Gunko, Svetlana Verbych, Mykhaylo Bryk, and Nidal Hilal: Concentration of apple juice using direct contact membrane distillation, Desalination 190 (2006) 117-124.

[5] Sanjay Nene, Suhkvinder Kaur, K. Sumod, and Bhagyashree Joshi: Membrane distillation for the concentration of raw cane-sugar syrup and membrane clarified sugarcane juice, Desalination 147 (2002) 157-160. 
[6] Martinez-Diez L., Florido-Diaz F., and Vazquez-Gonzalez M.I.: Study of evaporation efficiency in membrane distillation, Desalination 126 (1999) 193198.

[7] Termpiyakul P., Jiraratananon R, and Srisurichan S.: Heat and mass transfer characteristics of a direct contact membrane distillation process for desalination, Desalination 177 (2005) 133-141.

[8] Martinez-Diez L., and Vazquez-Gonzalez M.I.: Temperature and concentration polarization in membrane distillation of aqueous solutions, J. Membr. Sci 156 (1999) 265-273.

[9] Ping Peng, Fane A.G., and Xiaodong Li: Desalination by membrane distillation adopting a hydrophilic membrane, Desalination 173 (2005) 45-54.

[10] Rodriguez-Maroto J.M. and Martinez L: Bulk and measured temperatures in direct contact membrane distillation, J of Membr. Sci. 250 (2005) 141-149

[11] Ali K. Abdel-Rahman, Abdul Aziz A. Abbara, and Mohamed R. Bayoumi: Numerical modeling of concentration profiles in membrane channel, J. Eng. Sci., Assiut University 34 (2006) 251-274.

[12] Anderson, D.A., Tannehill, J.C. and Pletcher, R.H.: Computational fluid mechanics and heat transfer, Hemisphere Publishing Corporation, New-York, 1984.

[13] Phattaranawik J., Jiraratananon R., and Fane A.G.: Effect of pore size distribution and air flux on mass transport in direct contact membrane distillation, J. Membr. Sci. 215 (2003) 75-85.

[14] Martinez-Diez L., Vazquez-Gonzalez M.I., and Florido-Diaz F.: Study of membrane distillation using channel spacers, J. Membr. Sci 144 (1998) 45-56.

[15] Ali K. Abdel-Rahman: Flow and Heat Transfer Characteristics of Internal Flows with Fluid Injection, Ph. D. Thesis, Kyoto University, Kyoto, Japan, 1992.

[16] Geraldes, V., Semião, V. and Pinho, M. N. de: Numerical modeling of mass transfer in slits with semi-permeable membrane walls. Engineering Computations, 17 (2000) 192-217.

[17] Ali K. Abdel-Rahman, and Suzuki, K.: Laminar channel flow with fluid injection accounting for the flow in the porous wall, Proceedings of the $5^{\text {th }}$ Int. Conference of Fluid Mechanics, Cairo, (1995), 367-379.

[18] Geraldes, V., Semião, V. and Pinho, M.N.de, Flow and mass transfer modeling of nanofiltration. J Membr. Sci. 191 (2001) 109-128.

[19] Partakar, S. V. and Spalding, D. B.: A calculation procedure for heat, mass and momentum transfer in three-dimensional parabolic flows. Int. J Mass and Heat Transfer, 15 (1972) 1787-1806.

[20] EL-Dessouky H.T. and Ettouney H.M.: Fundamentals of Salt Water Desalination, Elsevier, Amsterdam, 2002.

[21] Kevin W. Lawson, and Douglas R. Lloyd: Membrane distillation. II. Direct contact MD, J. Membr. Sci 120 (1996) 123-133.

[22] Yanbin Yun, Runyu Ma, Wenzhen Zhang, Fane A.G., and Jiding Li: Direct contact membrane distillation mechanism for high concentration $\mathrm{NaCl}$ solutions, Desalination 188 (2006) 251-262. 
نمذجة توزيعات درجات الحرارة وتركيز الملح في التقطير بأغثية الاتصال المباشر (DCMD)

\author{
على كامل عبد الرحمن \\ قسم الهندسة الميكانيكية - كلية الهندسة \\ جامعة أسيوط - أسيوط 71516 - جمهورية مصر العربية
}

تقنيات تحلية المياه الحديثة المستخدمة في تحلية مياه البحر والمياه غير العذبة نوفر بدائل فعالة في العديد من الحالات. نظرا لاستهلاكها المنخفض من الطاقة، ظروف التشغيل سهلة المنال، والصيانة البسيطة، فإن تقنية النقطير بالأغشية (MD) أصبحت واحدة من أرخص تقنيات تحلية مياه البحر ـ القوة الدافعة للنقطير بالأغشية هي عبارة عن الفرق في ضغط البخار الذي يمكن الحصول عليه من خلال وجود محلول عند درجة حرارة أقل من درجة حرارة محلول التغذية بحيث يتلامس مباشرة مع جانب لانب النفاذ للغشاء مما يهيئ النمط المعروف باسم التقطير بأغشية الاتصال المباشر (DCMD).

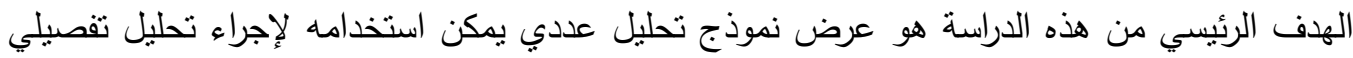

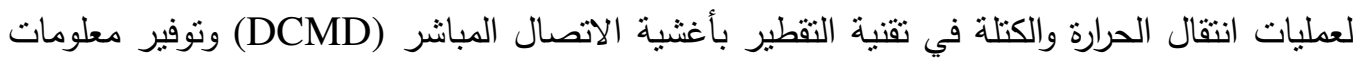

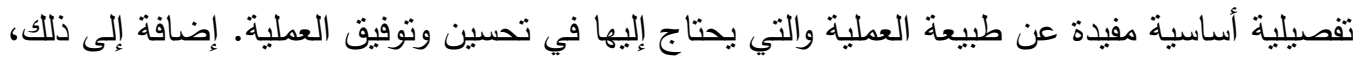

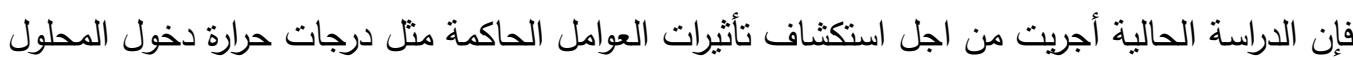

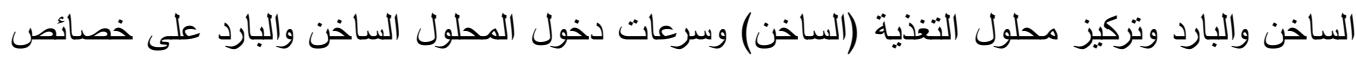
تقنية الثقطبر بأغشية الاتصال المباشر DCMD) من خلال تقييم معدلات التقطير والكفاءة الحرارية للعملية. عملية التقطير باستخدام أغشية الاتصال المباشر أمكن نمذجتها كمسألة مرتبطة ثنائبة الأبعاد والتي يتم فيها الحل العددي المتزامن لمعادلات الحفظ لانتقال كمية الحركة، الطاقة والكتلة لكل من المحلول

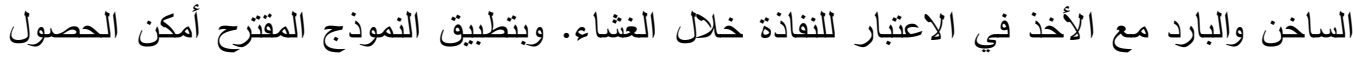

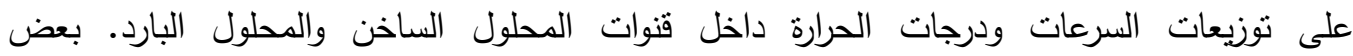
الاستتناجات الأساسية التي أمكن الحصول عليها ايضا من هذه الدراسة تتمثل في الآتي: (1) زيادة درجة

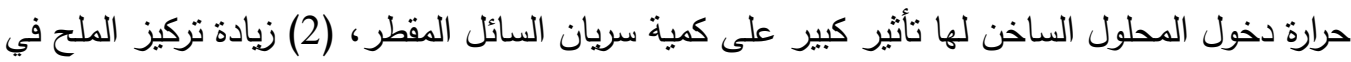
محلول التغذية تؤدي إلى انخفاض كمية سريان السائل المقطر ، (3) سرعات دخول المحلول الساخن والبارد لها نأثثر محدود نسبيا على كمية سريان السائل المقطر . 